\title{
Beyond Education: The Role of Research Universities in Innovation Ecosystems
}

\author{
Paola Rücker Schaeffer ${ }^{\text {a }}$ \\ PhD Student, paolaschaeffer@ige.unicamp.br \\ Bruno Fischer ${ }^{b}$ \\ Assistant Professor, bruno.fischer@fca.unicamp.br \\ Sérgio Queiroz ${ }^{\text {a }}$ \\ Associate Professor, squeiroz@ige.unicamp.br \\ a Department of Science and Technology Policy, University of Campinas, Carlos Gomes Street 250, Campinas - \\ SP, Brazil, 13083-855 \\ b School of Applied Sciences, University of Campinas, Pedro Zaccaria Street, 1300, Limeira — SP, Brazil, CEP \\ 13484-350
}

\begin{abstract}
$\mathrm{U}$ niversities are increasingly perceived as agents involved in regional development. It is now recognized that academic contributions to the socioeconomic environment go well beyond scientific investigation and teaching activities, and incorporate market-oriented initiatives to the academic mission. However, these effects are geographically bounded. Given these conditions, this article aims at addressing universities' impacts upon output vectors of localized innovation ecosystems. Using data from cities and microregions in the state of São Paulo, Brazil observed throughout the period of 2002-2014, we address universities' effects upon the locallevel generation of patents and utility models, software production and emergence of knowledge-intensive entrepreneurship. Besides the scant available evidence on innovation ecosystems located outside developed economies, dealing with a developing country also means we are addressing an analytical unit in which universities play a critical role in terms of knowledge production and

diffusion, a function of the weak competences of local firms.

Findings support the hypothesis that major academic institutions lie at the heart of innovation ecosystems, but impacts are mostly local, happening more strongly at the level of cities. While the formation of human capital also contributes to innovative output, its impacts are of minor relevance as compared to higher education institutions that achieve excellence in research. This poses severe challenges for policymakers when targeting the formation and enhancement of initiatives to develop innovative ecosystems, particularly for peripheral areas. First, these regions are not likely to reap substantial benefits from proximity to successful hubs. Beyond that, creating local conditions is not as straightforward as sometimes announced in political discourse. In this regard, some fundamental vectors are not easily manipulated in the short-term and there seems to be fundamental importance attributed to long-term, evolutionary conditions. Such is the case for high-quality universities.
\end{abstract}

\section{Keywords:}

regional systems of innovation; innovation ecosystems; universities. Innovation Ecosystems. Foresight and STI Governance, vol. 12, no 2, pp. 50-61. DOI: 10.17323/2500-2597.2018.2.50.61 
$\mathrm{U}$ niversities can be perceived as institutions that shape research activities, create a supply of qualified labor, and generate and diffuse knowledge across socioeconomic systems [Clark, 2004; Etzkowitz, Leydesdorff, 2000]. Accordingly, they function as agents involved in regional development through direct and indirect contributions to productive structures [Mowery, Sampat, 2005]. It is within this context that the concept of the 'entrepreneurial university' has gained ground [Etzkowitz, 1998, 2004]. Following this rationale, universities' contributions to society go well beyond scientific investigation and teaching activities, but also incorporate market-oriented initiatives into the academic mission. Such a perspective places an emphasis upon university-industry interactions, research contracts, consultancy, patenting, and licensing of research results, as well as academic entrepreneurship [Bercovitz, Feldman, 2006; D'Este, Perkmann, 2011; Perkmann et al., 2013].

In this regard, literature underscores the key role performed by these institutions within the context of innovation ecosystems. The main impacts are attributed to the supply of human capital [Benneworth, Hospers, 2007; Youtie, Shapira, 2008], collaborative research with industry leading to an upsurge in patenting, co-patenting, and scientific publications [Cowan, Zinovyeva, 2013; Hong, 2008; Jaffe, 1989; Fritsch, Slavtchev, 2007; Wal, Boschma, 2009], and a spawning of new, knowledge-intensive businesses [Agrawal, Cockburn, 2003; Feldman, 2001; Saxenian, 2006; WEF, 2013]. Consequently, academia does not only enhance capabilities in incumbent firms, but also is responsible for creating entirely new enterprises [Collini, 2012].

However, these effects are geographically bounded as they are connected to the industrial structure of each region, the characteristics of its firms, the patterns of existing connections among agents, and the intrinsic traits of individual universities [Agrawal, Cockburn, 2003; Bercovitz, Feldman, 2006; Buesa et al., 2006]. Hence, it is not the mere presence of universities that drives the consolidation of innovation ecosystems [Brown, 2016]. 'Soff' infrastructure, consisting of dynamic relationships involving universities, research institutes, firms, and other support institutions is necessary. These are the conditions needed for the generation of human resources that fit regional needs as well as for the accumulation and transfer of knowledge [Buesa et al., 2006].

Given these conditions, this article aims at addressing universities' impacts upon the output vectors of localized innovation ecosystems. We want to further understand the extent of academic contributions to these productive structures. Additionally, we also focus on the distinct geographical units in order to assess the spatial reach of such effects. In order to accomplish these goals, we assess data from the State of São Paulo, Brazil. The application of the empirical model comprises data coming from 645 cities and 43 microregions observed throughout the period of 2002-2014. As indicators of innovative ecosystems' output, we look into patents and utility models, software production, and the emergence of knowledge-intensive entrepreneurship (KIE) activity. Estimations control for other vectors of interest, including market size, agglomeration economies, localization economies, local infrastructure, and internationalization. Findings support the proposition that major academic institutions lie at the heart of innovation ecosystems, but impacts are mostly local, happening more dramatically at the level of cities.

This research is relevant as it pertains to an emerging economy. Besides the scant available evidence on innovation ecosystems located outside developed economies, dealing with a developing country also means we are addressing an analytical unit in which universities play a key role in terms of knowledge production and diffusion, which is a function of the weak competences of local firms. Hence, in nations that lag behind in innovation activities, universities can be understood as institutions capable of leveraging aggregate competitiveness thus shaping the conditions for the catching-up processes [Mazzoleni, Nelson, 2007; Suzigan, Albuquerque, 2011; Suzigan et al., 2009].

\section{Innovation Ecosystems}

The growing importance attributed to innovation as a mechanism of economic development has generated a large body of research that aims at understanding how agents and their respective patterns of interaction are related - and how, ultimately, they can boost innovative capabilities. One approach of key interest within this sphere deals with the dynamics of Regional Systems of Innovation. These local units are defined as systems "in which firms and other organizations are systematically engaged in interactive learning through an institutional milieu characterized by embeddedness" [Cooke et al., 1998, p. 1581].

Regional Systems of Innovation, or innovation ecosystems as they have been addressed more recently, are characterized by innovative activities that rely on collaborative arrangements between firms and local institutions, including universities, research institutes, technology transfer offices, sources of funding, and others. Within this context, innovative culture and policy are fundamental drivers in setting the conditions for interactions [Asheim, Isaksen, 2002; Cooke et al., 1997; Doloreux, 2002; Doloreux, Parto, 2005]. This (eco)systemic nature of the relationships can only arise in local contexts where the productive 
(knowledge exploitation subsystem) and the knowledge (knowledge generation subsystem) structures are engaged in processes of interactive learning [Clarysse et al., 2014; Cooke, 2001; Jiao et al., 2016]. Hence, innovation ecosystems/regional systems can be understood as dynamic systems, possessing an inherently social character and being composed by the interaction of its subsystems [Cooke, 2005; Uyarra, 2010].

The main argument behind this rationale is related to the idea that the generation and diffusion of innovations, as well as entrepreneurial activity, are shaped by the local infrastructure, its externalities, specialized services, and levels of trust involved in relationships between agents. In its turn, these dynamics lead to localized economic development [Alvedalen, Boschma, 2017]. One of the key aspects in this debate concerns the existence of multidimensional contexts, which are dependent upon the interactions among agents (non-linearity), characterized by systemic relationships and bound by historical trajectories that lead to spatially constrained learning processes. This latter proposition is a function of the fact that networks of interaction are fundamentally embedded in local productive structures since geographical proximity is a key determinant of knowledge sharing [Agrawal, Cockburn, 2003; Asheim et al., 2011], especially those of a tacit nature [Leydesdorff, Fritsch, 2006; Cooke, 2008].

Hence, spatial proximity, the existence of common institutions, along with formal and informal mechanisms forging trust in relationships, facilitate effective knowledge flows [Asheim, Coenen, 2005; Cooke, 2001; Jackson, 2011; Uyarra, 2010; Wal, Boschma, 2009]. In addition, the diffusion of knowledge between firms is also influenced by other elements, such as the distinct learning trajectories and capability building processes of firms [Boschma, 2005; Breschi, Lissoni, 2009; Doloreux, 2002; Dosi, 1988; Giuliani, 2013].

Furthermore, the spatial proximity is of utmost relevance for establishing interactions with universities and research institutes [Fritsch, 2001; Fritsch, Slavtchev, 2007; Moodysson et al., 2008; Uyarra, 2010], making the case for academic units to be considered the 'anchors' of innovation ecosystems, which foster aggregate competitiveness at the local level [Xu et al., 2017]. This situation underscores the importance assigned to universities as central agents in the processes of knowledge absorption and diffusion within regions, furthermore they also connect agents to external systems and reduce the risks of lock-in [Fritsch, Schwirten, 2006].

\section{Universities at the Heart of Innovation Ecosystems}

Universities are agents that generate and diffuse knowledge as well as promote regional development through its connections with the socioeconomic environment [Jiao et al., 2016; Poods et al., 2010]. Accordingly, these academic institutions lie at the heart of innovation ecosystems, feeding the local environment with qualified labor, interacting with local businesses, generating patents (and licensing these patents) and new ventures, attracting investments from incumbents, and acquiring and disseminating external knowledge [Benneworth, Hospers, 2007; Bercovitz, Feldman, 2006; Fritsch, Schwirten, 2006; Galan-Muros, Davey, 2017; Harrison, Leitch, 2010; Youtie, Shapira, 2008]. These activities endow universities with an entrepreneurial character, including market-related initiatives [Etzkowitz, 1998, 2004; Siegel, Wright, 2015].

As already outlined, spatial proximity matters when accounting for the impacts of universities upon the dynamics of innovation ecosystems [Hong, 2008; Jiao et al., 2016], a function of the high levels of tacit knowledge involved in the knowledge flows between academia and industry [Fritsch, Schwirten, 2006]. Illustratively, Ács et al. [Ács et al., 2002] note that the effects of academic R\&D in the United States are circumscribed within a radius of roughly 75 miles. Fritsch [Fritsch, 2005] corroborates with these findings, pointing out that university-industry relationships in Europe are essentially local. Such effects are magnified when the analytical subject concerns academic spin-offs, where the location of new ventures is closely connected to the location of universities [Asheim et al., 2011; Harrison, Leitch, 2010].

The role attributed to universities in the dynamics of innovation ecosystems is even more critical when the focus is directed towards the context of developing countries [Chen, Kenney, 2007; Cowan, Zinovyeva, 2013]. In these countries, universities stand out as influential agents in the process of technological improvement and catch up [Jiao et al., 2016; Li, 2009; Youtie, Shapira, 2008]. This happens as a consequence of the low levels of innovative capabilities embedded in firms, making academia a strategic source of information, knowledge, and innovation [Rapini et al., 2009].

However, this is far from representing a deterministic prerequisite for universities' contributions to innovation ecosystems. Even if its local presence can be interpreted as a prerequisite for regional systems of innovation [Bercovitz, Feldman, 2006; Hong, 2008], other elements of technological infrastructure and the very quality of universities' research capabilities are indispensable for knowledge flows to occur and confer itself and other agents with enhanced competitiveness [Cowan, Zinovyeva, 2013]. 


\section{Universities' Spillovers}

Patents are recognized by the literature as a key area of interest when analyzing the economic impacts of universities at the local level. Accordingly, the generation of intellectual property seems to be positively affected by academic expenditures on research activities [Jaffe, 1989]. Agrawal and Cockburn [Agrawal, Cockburn, 2003], Cowan and Zinovyeva [Cowan, Zinovyeva, 2013] and Li [Li, 2009] observe the existence of a 'co-location' effect between overall patenting activity in a given technological domain and the existence of strong academic research in the same domain in the same region. Buesa et al. [Buesa et al., 2010] identify universities as determinants of per capita patenting activity. Moreover, patent deposits performed by firms have a high propensity of citing academic publications that are produced in the same area, highlighting the spatial boundedness of these connections [Hicks et al., 2001].

In turn, the generation of academic spin-offs can also be deemed an important source of economic impact arising from universities within the context of innovation ecosystems [Bercovitz, Feldman, 2006; Chen, Kenney, 2007; WEF, 2014]. Following this rationale, the importance of academic entrepreneurship as a mechanism of research commercialization has received increasing attention from the literature on entrepreneurial universities [Galan-Muros, Davey, 2017]. Since new ventures are mostly embedded within the social context, their creation often takes place within ecosystems where universities have established connections with other agents [Alvedalen, Boschma, 2017]. Furthermore, universities can be considered the key drivers in instituting and developing new knowledge-intensive firms, as identified in the case of Beijing [Chen, Kenney, 2007]. In this way, universities take on a double function, interacting and collaborating not only with incumbents, but also giving birth to new enterprises [Collini, 2012]. Therefore, we expect knowledge-intensive entrepreneurial activity to be significantly influenced by the local presence of academia within innovation ecosystems in emerging economies following recent evidence

\section{Methodological Procedures and Data}

A first step in our assessment consists of assembling an empirical model aimed at testing the role of universities in shaping the capabilities of innovation ecosystems. As shown in our theoretical background, the underlying hypothesis of this model must reflect the expectations that academic institutions function as central agents within the local and regional dynamics of innovative activity [Asheim et al., 2011; Autio, 1998; Bercovitz, Feldman, 2006; Clarysse et al., 2014; Cooke et al., 1997; Diez, 2000; Guerrero et al., 2016; Mazzoleni, Nelson, 2007]. To this end, we propose the following analytical structure:

$Y_{i t}=\alpha+U n i v_{i t}^{\beta}+\sum i \Omega_{i t}^{\theta}+\varepsilon_{i t}$

Where $Y_{i t}$ represents any given output of innovation ecosystems in location ' $\mathrm{i}$ ' in time ' $\mathrm{t}$ '. $\alpha$ is a constant. $U n i v_{i t}^{\beta}$ stands for universities' impacts upon the outcomes with elasticity $\beta$. The term $\sum i \Omega_{i t}^{\theta}$ determines the aggregate behaviour of controls and other potential sources of influence on $Y_{i t}$ with a combined elasticity $\theta$. The main effects here can be associated with local market dynamics, the infrastructure, and level of internationalization (see Table 1 for a description of operational variables). $\boldsymbol{\varepsilon}_{\boldsymbol{i}}$ is the model's error term.

The application of the empirical model comprises data coming from 645 cities and 43 microregions $^{1}$ in the State of São Paulo observed over the course of 13 years (2002-2014). This geographic scope justifies city-level analysis as an adequate subject for the evaluation of innovation ecosystems [Qian et al., 2013], but the expansion of the analysis can offer insights into the spatial reach of universities' influence on innovative performance. The complete set of analytical variables is depicted in Table 1.

Our outcome variable, $Y$, is assessed through three different indicators aimed at generating a multidimensional perspective of innovation ecosystems, namely: (i) patents and utility models; (ii) software production; and (iii) knowledge-intensive entrepreneurship (KIE) activity. While the first two variables are straightforwardly represented by traditional intellectual property statistics, KIE activity is approximated by the number of PIPE projects within a city/region in a given year. This program is an initiative from FAPESP (the research funding agency of the State of São Paulo) to support innovation in small enterprises, resembling the structure and objectives of the Small Business Innovation Research (SBIR) program in the United States ${ }^{2}$. We estimate the model for KIE including transformed (binary)

\footnotetext{
${ }^{1}$ According to the definition of micro-regions adopted by the São Paulo Statistics Office. Their nomenclature refers to these geographic areas as 'Regions of Government'.

${ }^{2}$ It is important to note that academic degrees or formal appointments at universities are not among the conditions for receiving grants for projects. Instead, priority is given to individuals with previous professional experience and technical capabilities. This feature of PIPE substantively reduces biases towards cities that contain university campuses.
} 
Table 1. Analytical Variables

\begin{tabular}{|c|c|c|}
\hline Variable & Description & Source of data \\
\hline Patents and Utility Models & $\begin{array}{l}\text { Sum of deposits of patents and utility models assigned } \\
\text { to a city/region in a given year. }\end{array}$ & Brazilian Patent Office \\
\hline Software & $\begin{array}{l}\text { Amount of software developed by residents of a city/ } \\
\text { region in a given year. }\end{array}$ & Brazilian Patent Office \\
\hline KIE & $\begin{array}{l}\text { Sum of entrepreneurial projects' grants (PIPE/ } \\
\text { FAPESP) assigned to a city/region in a given year. }\end{array}$ & São Paulo Research Foundation, FAPESP \\
\hline GDP & $\begin{array}{l}\text { City-/Regional-level gross domestic product. Data in } \\
\text { current local currency. }\end{array}$ & São Paulo Statistics Office \\
\hline Population & Total inhabitants. & São Paulo Statistics Office \\
\hline Population Density & Inhabitants per square kilometer & São Paulo Statistics Office \\
\hline LQ KIA & $\begin{array}{l}\text { Location Quotient of Knowledge-Intensive Activities } \\
\text { in a city/region in a given year*. }\end{array}$ & $\begin{array}{l}\text { Calculated based on data from the Brazilian } \\
\text { Ministry of Labor }\end{array}$ \\
\hline Infrastructure Investments & $\begin{array}{l}\text { City/regional level investments in infrastructure. Data } \\
\text { in current local currency. }\end{array}$ & São Paulo Statistics Office \\
\hline Energy Consumption & Consumption of electric energy (MWh). & São Paulo Statistics Office \\
\hline Incubators and Science Parks & $\begin{array}{l}\text { Binary variable. It takes the value of ' } 1 \text { ' if the city/ } \\
\text { region possesses a business incubator and/or a science } \\
\text { park; ' } 0 \text { ' if otherwise. }\end{array}$ & São Paulo Investment Promotion Agency \\
\hline Trade & $\begin{array}{l}\text { Sum of imports plus exports. Data in current local } \\
\text { currency. }\end{array}$ & São Paulo Statistics Office \\
\hline Enrollment in HEIs & $\begin{array}{l}\text { Share of the population enrolled in Higher Education } \\
\text { Institutions. }\end{array}$ & São Paulo Statistics Office \\
\hline High-Quality University & $\begin{array}{l}\text { Presence of at least one high-quality university campus } \\
\text { in the city/region. }\end{array}$ & Scimago Ranking \\
\hline $\begin{array}{l}\text { High-Quality University } \\
\text { System }\end{array}$ & $\begin{array}{l}\text { Presence of two or more high-quality university } \\
\text { campus in the city/region. }\end{array}$ & Scimago Ranking \\
\hline \multicolumn{3}{|c|}{$\begin{array}{l}\text { * The quotient is given by: } \\
\left(\frac{K I A_{i t}}{T F_{i t}}\right) /\left(\frac{K I A_{S t}}{T F_{S t}}\right) \text {, } \\
\text { where KIA corresponds to total knowledge-intensive firms and TF represents total firms. First, we assess KIA's weight in location "i", period " } \mathrm{t} \text { " as a share } \\
\text { of TF in this location, then we analyze the local specialization respective to the State ("S") profile. The following Knowledge-Intensive Sectors were used } \\
\text { for the Location Quotient (LQ KIA) Analysis (NACE Rev. } 2 \text { - } 2 \text { Digits): Manufacture of chemicals and chemical products (20), Manufacture of rubber } \\
\text { and plastic products (22), Manufacture of computer, electronic and optical products (26), Manufacture of motor vehicles, trailers and semi-trailers (29), } \\
\text { Repair and installation of machinery and equipment (33), Computer programming, consultancy and related activities (62), Information service activities } \\
\text { (63), Activities auxiliary to financial services and insurance activities (66), Legal and accounting activities (69), Activities of head offices; management } \\
\text { consultancy activities (70), Architectural and engineering activities; technical testing and analysis (71), Scientific research and development (72), Adver- } \\
\text { tising and market research (73), Other professional, scientific and technical activities (74). } \\
\text { Source: compiled by the authors. }\end{array}$} \\
\hline
\end{tabular}

forms of patenting activity and software production, as these indicators can feed entrepreneurs with inputs for firm-level innovation ${ }^{3}$.

Our main target concerns the contributions made by high-quality academic universities as influential agents within innovation ecosystems. In order to achieve robust results, the corresponding indicators of these institutions were differentiated based upon the following: (i) the presence of at least one campus of a high-quality university; and (ii) the presence of a 'system' of high-quality university campuses, i.e., presence of two or more units of these institutions at the city/regional-level. The use of dummy variables follows the analytical approach found in [Fischer et al., 2018a; Alcácer, Chung, 2007]. The focus on toptier institutions is based upon [Laursen et al., 2011].

The operational definition of high-quality universities was built upon institutions located in the State of São Paulo and appearing in the Scimago ranking . Non-university institutions were excluded. We also excluded universities that did not consistently qualify for the ranking. We interpreted this situation as an indicator of 'shaky' quality. If an institution entered the ranking and remained on it for at least four years in a row, we added it to the sample as a high-quality university beginning with its first year of inclusion. This procedure allows us to add universities that have demonstrated improved quality over the period of study. Furthermore, some institutions and campuses began operations after the initial year of the

\footnotetext{
${ }^{3}$ Provided that these variables present extreme levels of concentration (particularly for city-level analysis), their treatment as predictors becomes troublesome. See details on estimation procedures for these indicators as dependent variables below.

${ }^{4}$ For further details on the Scimago Institutions Rankings Methodology, see: http://www.scimagoir.com/methodology.php. For the years not covered by the ranking, we applied the same methodology of inclusion as the one used by Scimago.
} 
Table 2. City-level Descriptive Statistics

\begin{tabular}{|c|c|c|c|c|c|}
\hline Variable & $\mathbf{N}$ & Minimum & Maximum & Mean & Std. Deviation \\
\hline Patents & 8385 & 0.00 & $1,444.00$ & 4.28 & 50.09 \\
\hline Software & 8385 & 0.00 & 237.00 & 0.60 & 8.36 \\
\hline KIE & 8385 & 0.00 & 33.00 & 0.10 & 1.07 \\
\hline GDP & 8385 & $6,233,930.00$ & $628,064,882,140.00$ & $1,705,420,922.98$ & $16,340,733,232.15$ \\
\hline Population & 8385 & 800.00 & $11,513,836.00$ & $62,590.08$ & $447,177.19$ \\
\hline Population Density & 8385 & 3.73 & $12,796.46$ & 294.47 & $1,170.44$ \\
\hline LQ KIA & 8385 & 0.00 & 5.25 & 0.49 & 0.42 \\
\hline Infrastructure Investments & 8385 & 0.00 & $4,397,255,759.00$ & $12,917,986.01$ & $117,447,952.00$ \\
\hline Energy Consumption & 8385 & 655.00 & $30,073,839.00$ & $180,139.83$ & $1,094,208.41$ \\
\hline Incubators and Science Parks & 8385 & 0.00 & 1.00 & 0.03 & 0.16 \\
\hline Trade & 8385 & 0.00 & $23,814,616,506.00$ & $154,078,636.26$ & $932,951,809.40$ \\
\hline Enrollment in HEIs & 8385 & 0.00 & 0.28 & 0.01 & 0.02 \\
\hline High-Quality University & 8385 & 0.00 & 1.00 & 0.05 & 0.22 \\
\hline High-Quality University System & 8385 & 0.00 & 1.00 & 0.01 & 0.12 \\
\hline
\end{tabular}

analysis, so we controlled effects to state either when the campus began its operation (in the case of being a campus belonging to an institution already identified as high quality) or, in the case of a new institution, when it achieved 'high-quality' status according to the defined parameters.

In total, we have a sample of fifteen high-quality universities located in 37 cities and 25 microregions. In order to verify the robustness of our procedure, we cross-checked our sample with data from the São Paulo Research Foundation (FAPESP) Grants and Scholarships database. The locations selected as having high-quality universities corresponded to the group of relevant cities/microregions in terms of research funding. We complemented this analysis with the variable Enrollment in HEIs. While this indicator somewhat overlaps with the presence of high-quality universities, it better reflects the overall supply of an educated workforce, not necessarily capturing academic research and its associated effects. This allows us to address the impacts arising from both academic research and teaching, thus offering a comprehensive picture of universities' impacts upon innovation ecosystems.

Ancillary variables (included in the vector $\Omega$ ) control for market size (GDP, Population), agglomeration economies (Population Density), localized economies (Location Quotient of Knowledge-Intensive Activities - LQ KIA ${ }^{5}$ ), local infrastructure (Infrastructure Investments, Energy Consumption ${ }^{6}$, and Incubators \& Science Parks), and internationalization (Trade). Although not exhaustive, these indicators offer a comprehensive set of controls for the performance of innovation ecosystems.

Concerning our evaluation strategy, as we are dealing with small numbers given the city/year structure of our analysis, analyses were carried out with General Linear Models for count data. Given the presence of overdispersion in the sample for both cities and microregions, Negative Binomial approaches were applied. Continuous variables were addressed via natural logs to simplify the interpretation of the results.

\section{Results}

Before dedicating our attention to an analysis of the results of the evaluative models, we present the descriptive statistics (Tables 2 and 3) for the cities and microregions according to variables' natural structures (without logarithmic transformations). A noteworthy aspect in the dataset's structure concerns the number of zeros in some variables. This is of particular relevance for a city-level analysis. Such an outcome in this situation can be the generation of missing values that significantly reduce the sample for econometric estimations, although it still leaves us with a substantial number of observations for analytical purposes.

We begin our assessment with an evaluation of the results at the city-level. In line with the hypothesis presented in this paper's theoretical background, the presence of high-quality universities yields positive

\footnotetext{
${ }^{5}$ Knowledge-intensive activities entail an adaptation of the definitions provided by Ortega-Argilés et al.[Ortega-Argilés et al., 2011] for high-technology manufacturing activities, and Fischer [Fischer, 2015] for Knowledge-Intensive Business Services (KIBS).

${ }^{6}$ As infrastructure investments may suffer from simultaneity issues, we use energy consumption as a proxy for infrastructure quality (as in [Fischer et al., 2018a]).
} 


\section{Table 3. Microregion-level Descriptive Statistics}

\begin{tabular}{|l|c|c|c|c|c|}
\hline \multicolumn{1}{|c|}{ Variable } & N & Minimum & Maximum & Mean & Std. Deviation \\
\hline Patents & 559 & 0,00 & $1.951,00$ & 64,18 & 256,71 \\
\hline Software & 559 & 0,00 & 281,00 & 9,02 & 37,54 \\
\hline KIE & 559 & 0,00 & 47,00 & 1,57 & 4,81 \\
\hline GDP & 559 & $691.797 .400,72$ & $723.802 .678 .913,45$ & $19.994 .544 .928,05$ & $71.513 .895 .104,02$ \\
\hline Population & 559 & $104.656,00$ & $19.875 .809,00$ & $938.851,14$ & $2.812 .857,11$ \\
\hline Population Density & 559 & 23,08 & $3.019,21$ & 245,87 & 586,63 \\
\hline LQ KIA & 559 & 0,18 & 1,59 & 0,47 & 0,22 \\
\hline Infrastructure Investments & 559 & 0,00 & $7.496 .336 .686,06$ & $208.066 .415,95$ & $698.684 .753,55$ \\
\hline Energy Consumption & 559 & $120.541,25$ & $58.805 .957,45$ & $3.048 .096,38$ & $8.398 .491,30$ \\
\hline Incubators and Science Parks & 559 & 0,00 & 1,00 & 0,28 & 0,45 \\
\hline Trade & 559 & 0,00 & $54.966 .359 .270,60$ & $1.972 .653 .288,99$ & $6.533 .900 .871,03$ \\
\hline Enrollment in HEIs & 559 & 0,00 & 0,03 & 0,01 & 0,01 \\
\hline High-Quality University & 559 & 0,00 & 1,00 & 0,56 & 0,50 \\
\hline High-Quality University System & 559 & 0,00 & 1,00 & & 0,28 \\
\hline Source: compiled by the authors. & & & & & \\
\hline
\end{tabular}

and significant effects for all three dependent variables included in our calculations. This is valid for both variables representing these institutions (High-Quality University and High-Quality University System). These results seem to confirm the existence of a 'co-location' effect in terms of universities' spillovers as observed by [Agrawal, Cockburn, 2003; Cowan, Zinovyeva, 2013; Li, 2009] regarding the generation of patents. Additionally, we found evidence that an academic presence demonstrates heightened relevance as a driver of entrepreneurial activity [Bercovitz, Feldman, 2006; Chen, Kenney, 2007; Galan-Muros, Davey, 2017; WEF, 2014].

Interestingly, for software developments and KIE activity, the coefficient associated with the presence of at least one major university is greater than the effects from the existence of a system (at least two) of such

Table 4. City-level Estimates

\begin{tabular}{|c|c|c|c|c|c|c|}
\hline \multirow{2}{*}{ Variable } & \multicolumn{2}{|c|}{ Patents } & \multicolumn{2}{|c|}{ Software } & \multicolumn{2}{|c|}{ KIE } \\
\hline & I & II & I & II & I & II \\
\hline Constant & $-4.078^{* * *[0.871]}$ & $-3.224^{\star * *}[0.875]$ & $-4.799 * * *[1.876]$ & $-2.159[1.830]$ & $-3.507[2.504]$ & $-0.494[2.504]$ \\
\hline GDP & $-0.298^{\star * *}[0.100]$ & $-0.383^{* * *}[0.097]$ & $-0.128[0.249]$ & $-0.391^{\star}[0.234]$ & $-0.572^{*}[0.317]$ & $-0.778^{\star *}[0.305]$ \\
\hline Population & $0.438^{* * *}[0.095]$ & $0.556^{* * *}[0.093]$ & $-0.829^{* * *}[0.233]$ & $-0.544^{* *}[0.219]$ & $-0.013[0.278]$ & $-0.381[0.277]$ \\
\hline Population Density & $0.162^{\star * *}[0.036]$ & $0.158^{* * *[0.036]}$ & $0.503^{* * *[0.095]}$ & $0.526^{* * *}[0.096]$ & $-0.029[0.109]$ & $-0.045[0.107]$ \\
\hline LQ KIA & $0.737^{\star * *}[0.086]$ & $0.775^{\star * *}[0.087]$ & $1.241^{* * *}[0.197]$ & $1.172^{* * *}[0.195]$ & $0.668^{\star \star}[0.296]$ & $0.693^{* *}[0.288]$ \\
\hline $\begin{array}{l}\text { Infrastructure } \\
\text { Investments }\end{array}$ & $0.001[0.057]$ & $-0.005[0.056]$ & $0.080[0.155]$ & $0.151[.149]$ & $0.241[0.194]$ & $0.167[0.188]$ \\
\hline Energy Consumption & $0.389^{* * *}[0.097]$ & $0.401^{* * *}[0.097]$ & $0.877^{\star * *}[0.249]$ & $0.855^{\star * *}[.244]$ & $0.586^{*}[0.300]$ & $0.631^{\star *}[0.295]$ \\
\hline $\begin{array}{l}\text { Incubators and Science } \\
\text { Parks }\end{array}$ & $0.857^{\star * *}[0.108]$ & $0.751^{\star * *}[0.112]$ & $1.083^{\star * *}[0.255]$ & $1.090^{* * *}[.264]$ & $1.043^{* * *}[0.240]$ & $0.910^{\star * \star}[0.271]$ \\
\hline Patents Binary & - & - & - & - & $0.568[.389]$ & $0.884^{* *}[0.385]$ \\
\hline Software Binary & - & - & - & - & $0.802^{* * *}[0.214]$ & $0.926^{\star * *}[0.212]$ \\
\hline Trade & $0.070^{* * *}[0.022]$ & $0.061^{* * *}[0.022]$ & $0.125^{\star}[0.073]$ & $0.086[0.069]$ & $0.089[0.084]$ & $0.009[0.078]$ \\
\hline Enrollment in HEIs & $0.014[0.031]$ & $0.057^{\star}[0.030]$ & $0.393^{\star * *}[0.093]$ & $0.502^{\star * *}[0.090]$ & $0.072[0.118]$ & $0.268^{\star *}[0.111]$ \\
\hline $\begin{array}{l}\text { High-Quality } \\
\text { University }\end{array}$ & $0.604^{* * *}[0.094]$ & - & $1.233^{* * *}[0.228]$ & - & $1.661^{* * *}[0.226]$ & - \\
\hline $\begin{array}{l}\text { High-Quality } \\
\text { University System }\end{array}$ & - & $0.829^{* * *}[0.140]$ & - & $1.192^{* * *}[0.299]$ & - & $1.283^{\star * *}[0.288]$ \\
\hline Alpha & $0.875^{\star * *}[0.049]$ & $0.877^{* * *}[0.049]$ & $3.032^{* * *}[0.275]$ & $3.083^{* * *}[0.282]$ & $2.080^{* * *}[0.337]$ & $2.371^{\star * *}[0.384]$ \\
\hline Overdispersion & Yes & Yes & Yes & Yes & Yes & Yes \\
\hline Valid N & 1319 & 1319 & 1319 & 1319 & 1319 & 1319 \\
\hline
\end{tabular}


Table 5. Microregion-level Estimates

\begin{tabular}{|c|c|c|c|c|c|c|}
\hline \multirow{2}{*}{ Variable } & \multicolumn{2}{|c|}{ Patents } & \multicolumn{2}{|c|}{ Software } & \multicolumn{2}{|c|}{ KIE } \\
\hline & I & II & I & II & I & II \\
\hline Constant & $-10.614^{* * *}[1.755]$ & $-12.106^{\star \star *}[1.724]$ & $-27.160^{\star * *}[3.837]$ & $-27.323^{* * *[3.609]}$ & $-35.002[89.553]$ & $-31.191[81.024]$ \\
\hline GDP & $0.430^{* *}[0.177]$ & $0.474^{* * *}[0.179]$ & $1.799^{* * *}[0.380]$ & $1.837^{\star * *}[0.372]$ & $1.355^{\star *}[0.552]$ & $1.355^{\star \star}[0.572]$ \\
\hline Population & $0.710^{* * *}[0.157]$ & $0.671^{* * *}[0.160]$ & $-0.360[0.344]$ & $-0.323[0.340]$ & $-0.210[0.443]$ & $-0.361[0.456]$ \\
\hline Population Density & $0.026[0.065]$ & $-0.031[0.063]$ & $-0.020[0.155]$ & $-0.055[0.154]$ & $-0.381[0.238]$ & $-0.356[0.245]$ \\
\hline LQ KIA & $0.665^{\star * *}[0.141]$ & $0.517^{* * *}[0.141]$ & $0.681^{\star *}[0.304]$ & $0.784^{* * *}[0.294]$ & $1.295^{* * *}[0.402]$ & $0.772^{\star}[0.417]$ \\
\hline $\begin{array}{l}\text { Infrastructure } \\
\text { Investments }\end{array}$ & $-0.314^{* * *[0.089]}$ & $-0.251^{\star * *}[0.090]$ & $-0.239[0.206]$ & $-0.296[0.206]$ & $-0.624^{* *}[0.257]$ & $-0.443^{*}[0.260]$ \\
\hline Energy Consumption & $0.220^{* *}[0.105]$ & $0.255^{\star *}[0.105]$ & $-0.004[0.205]$ & $-0.001[0.201]$ & $0.218[0.275]$ & $0.354[0.281]$ \\
\hline $\begin{array}{l}\text { Incubators and } \\
\text { Science Parks }\end{array}$ & $0.673^{* * *}[0.095]$ & $0.737^{\star * *}[0.096]$ & $0.545^{\star *}[0.214]$ & $0.618^{* * *}[0.206]$ & $1.022^{\star * \star}[0.244]$ & $1.179^{* * *[0.237]}$ \\
\hline Patents Binary & - & - & - & - & $24.957[89.553]$ & $18.633[81.024]$ \\
\hline Software Binary & - & - & - & - & $0.640^{* * *}[0.240]$ & $0.595^{\star *}[0.247]$ \\
\hline Trade & $-0.159^{* * *}[0.043]$ & $-0.175^{\star * *}[0.044]$ & $-0.125[0.113]$ & $-0.117[0.111]$ & $-0.273^{*}[0.144]$ & $-0.325^{\star \star}[0.143]$ \\
\hline Enrollment in HEIs & $-0.086[0.053]$ & $-0.073[0.054]$ & $0.239 *[0.139]$ & $0.250 *[0.136]$ & $0.647^{* * *}[0.209]$ & $0.616^{\star * *}[0.218]$ \\
\hline $\begin{array}{l}\text { High-Quality } \\
\text { University }\end{array}$ & $0.400^{* * *}[0.092]$ & - & $-0.070[0.223]$ & - & $1.068^{\star \star \star}[0.316]$ & - \\
\hline $\begin{array}{l}\text { High-Quality } \\
\text { University System }\end{array}$ & - & $0.251^{\star * *}[0.094]$ & & $-0.301[0.199]$ & - & $0.721^{\star \star \star}[0.240]$ \\
\hline Alpha & $0.390^{* * *}[0.035]$ & $0.408^{* * *}[0.036]$ & $1.150^{* * *}[0.169]$ & $1.118^{* * *}[0.168]$ & $1.100^{* * *}[0.235]$ & $1.168^{\star * \star}[0.246]$ \\
\hline Overdispersion & Yes & Yes & Yes & Yes & Yes & Yes \\
\hline Valid N & 386 & 386 & 386 & 386 & 386 & 386 \\
\hline
\end{tabular}

institutions. Even for the case of patenting activity, the difference is not substantial. This is an interesting indicator of the role played by even one preeminent, research-oriented university within the city-level dynamics of innovation ecosystems. In any case, the impacts of these universities present a dominant behavior respective to most of the other variables included in the calculations.

Complementarily, when we address the levels of Enrollment in HEIs, it becomes clear that the impacts arising from the provision of an educated workforce can be beneficial for the local innovation environment. However, these effects are much more limited than those expected for high-quality academia. At least this seems to be the case for the State of São Paulo, Brazil. This situation highlights the strategic importance of major universities as research hubs that can improve the generation of knowledge and the emergence of new, innovation-driven firms.

A general evaluation of the other variables included in the calculations renders some noteworthy findings. For instance, agglomeration economies associated with the population density seem to be present for patenting activity and software production, in line with the extant literature on the geography of innovation (e.g. [Florida, Mellander, 2014]). However, these effects do not drive entrepreneurial activity, which supports recent evidence in the field [Fischer et al., 2018b]. Another area of great relevance concerns the existence of a support structure of local businesses in knowledge-intensive activities, a marked signal of localized economies as drivers of innovation ecosystems' capabilities [Delgado et al., 2010]. In turn, the incubators and science parks seem to play an important role in shaping local conditions for innovative output. Surprisingly, the levels of city-level internationalization are weakly related to the dependent variables, with the exception of patenting activity. Infrastructural conditions also perform as expected, providing innovation ecosystems with the necessary operational platforms, nonetheless, this is valid solely for the proxy Energy Consumption.

Turning to the analysis of microregions, we notice that effects associated with our three universityrelated variables (Enrollment in HEIs, High-Quality University, and High-Quality University System) are significantly diminished as compared to findings observed for the city-level analysis. Still, some significant impacts can still be observed, but with consistently reduced coefficients. This carries with it theoretical and methodological implications. From the perspective of theory, it implies that geographical spillovers are frail and that higher education institutions' impacts upon innovation ecosystem dynamics are mostly constrained to the level of cities. From a methodological point of view, this means that analytical approaches to these ecosystems should be directed toward these smaller geographic units. 
Per the remaining variables, some changes can be noted. Remarkably, the role of GDP is inverse to what was noticed in the previous step of the assessment. Latent agglomeration economies associated with population density vanish. This can be considered an expected outcome, as the benefits from agglomeration are likely to be weaker when larger areas are under scrutiny. Localized economies continue to play an important role, underscoring the strategic weight of a support business structure. In turn, infrastructural conditions lose importance, except for the specific case of business incubators and science parks. Again, internationalization levels perform poorly as drivers of output within the realm of innovation ecosystems.

\section{Conclusions}

In this article we have assessed the role of universities in shaping the dynamics of innovation ecosystems within the context of a particular developing country, Brazil. In order to do so, we designed an empirical approach that tests the relevance of the presence of high-quality universities in a given location as well as the overall supply of a qualified workforce (regardless of the quality of the alma mater). We then evaluated three outcome vectors of innovative activity, namely: patenting activity, software development, and knowledge-intensive entrepreneurship. Drawing on data from the State of São Paulo, we found consistent indicators that major academic institutions lie at the heart of innovation ecosystems, thus corroborating the 'anchor' hypothesis outlined in [Xu et al., 2017]. While the formation of human capital also contributes to innovative output, its impacts are of minor relevance compared to higher education institutions that achieve excellence in research.

These results highlight not only the importance of universities in structuring successful ecosystems, but it also demonstrates that encouraging research at such institutions can have pervasive impacts upon socioeconomic development at the local level. Yet, there remains the challenge of further integrating academia into the markets of Brazil. Achieving closer interactions between universities and commercial systems can boost technological innovation and, consequently, catch-up dynamics [Caraça et al., 2009; Cohen et al., 2002; Jiao et al., 2016; Li, 2009]. However, in the Brazilian context, these interconnections still suffer from institutional and market deficiencies [Fischer at al., 2018a]. Improvements in the conditions and incentives for these interactions, as we have demonstrated, can prove to be a fruitful strategy for the Brazilian Innovation System.

Interestingly, our empirical approach suggests that such effects are mostly circumscribed to cities, which suggests that larger regions might not be adequate geographic units for evaluating innovation ecosystems' development [Audretsch, Belitski, 2017; Bruns et al., 2017; Qian et al., 2013]. This finding emphasizes the importance of spatial proximity [Fritsch, Schwirten, 2006], but it also draws attention to the geographical limits of innovation spillovers. These conditions bring significant implications for the way in which innovation policies at the regional level are addressed, given that connections among ecosystems' dimensions seem to happen within restricted areas.

This poses severe challenges for policymakers when targeting the formation and enhancement of innovation ecosystems, particularly for peripheral areas. First, as outlined by our findings, these regions are not likely to reap substantial benefits from proximity to successful hubs, if that is even the case in the first place. Beyond that, creating local conditions is not as straightforward as sometimes announced by policymakers. Establishing incubators and science parks is good, but such initiatives are only part of ecosystems' structures. In this regard, some fundamental vectors are not easily manipulated in the short term and there seems to be fundamental importance attributed to long-term, evolutionary conditions. Such is the case for high-quality universities. These institutions cannot be simply instated in a given location by fiat, as new campuses may take an extensive amount of time to mature into preeminent schools and research centers. Complementarily, leading institutions are not likely to open new units indefinitely, which consequently leaves many locations without the key presence of these drivers of innovation at the local level.

We expect our contributions to generate further research on the role of academia in shaping the dynamics of innovation ecosystems of developing countries. While case studies and econometric analyses exist for developed economies, there are few approaches dealing with the reality of relatively laggard systems, where the connections between the necessary agents are still immature [Rapini et al., 2009]. Avenues for future studies should include additional and alternative qualifications for the presence of a university, as well as a deep dive into the qualitative nature of academic research as a driver for innovative activity at the city level. These studies will help in creating a body of knowledge that can feed the policymaking process with more informative insights than those generated by anecdotal evidence collected from dissimilar contexts. 


\section{References}

Ács Z.J., Anselin L., Varga A. (2002) Patents and innovation counts as measures of regional production of new knowledge. Research Policy, vol. 31, no 7, pp. 1069-1085.

Agrawal A., Cockburn I. (2003) The anchor tenant hypothesis: Exploring the role of large, local, R\&D-intensive firms in regional innovation systems. International Journal of Industrial Organization, vol. 21, no 9, pp. 1227-1253.

Alcácer J., Chung W. (2007) Location strategies and knowledge spillovers. Management Science, vol. 53, no 5, pp. 760-776.

Alvedalen J., Boschma R. (2017) A critical review of entrepreneurial ecosystems research: Towards a future research agenda. European Planning Studies, vol. 25, no 6, pp. 887-903.

Asheim B., Coenen L. (2005) Knowledge Bases and Regional Innovation Systems: Comparing Nordic clusters. Research Policy, vol. 34, no 8, pp. 1173-1190.

Asheim B., Isaken A. (2002) Regional Innovation Systems: The integration of local 'sticky' and global 'ubiquitous' knowledge. Journal of Technology Transfer, vol. 27, no 1, pp. 77-86.

Asheim B., Smith H., Oughton C. (2011) Regional Innovation Systems: Theory, Empirics and Policy. Regional Studies, vol. 45, no 7, pp. 875-891.

Audretsch D., Belitski M. (2017) Entrepreneurial ecosystems in cities: Establishing the framework conditions. Journal of Technology Transfer, vol. 42, no 5, pp. 1030-1051.

Autio E. (1998) Evaluation of RTD in regional systems of innovation. European Planning Studies, vol. 6, no 2, pp. 131-140.

Benneworth P., Hospers G.J. (2007) The new economic geography of old industrial regions: Universities as globallocal pipelines. Environment and Planning, vol. 25, no 6, pp. 779-802.

Bercovitz J., Feldman M. (2006) Entrepreneurial universities and technology transfer: A conceptual framework for understanding knowledge-based economic development. Journal of Technology Transfer, vol. 31, no 1, pp. 175-188.

Boschma R. (2005) Proximity and innovation: A critical assessment. Regional Studies, vol. 39, no 1, pp. 61-74.

Breschi S., Lissoni F. (2009) Mobility of skilled workers and co-invention networks: An anatomy of localized knowledge flows. Journal of Economic Geography, vol. 9, no 4, pp. 439-468.

Brown R. (2016) Mission impossible? Entrepreneurial universities and peripheral regional innovation systems. Industry and Innovation, vol. 23, no 2, pp. 189-205.

Bruns K., Bosma N., Sanders M., Schramm M. (2017) Searching for the existence of entrepreneurial ecosystems: A regional cross-section growth regression approach. Small Business Economics, vol. 49, no 1, pp. 31-54.

Buesa M., Heijis J., Baumert T. (2010) The determinants of regional innovation in Europe: A combined factorial and regression knowledge production function approach. Research Policy, vol. 39, no 6, pp. 722-735.

Buesa M., Heijis J., Pollitero M.M., Baumert T. (2006) Regional systems of innovation and the knowledge production function: The Spanish case. Technovation, vol. 26, no 4, pp. 463-472.

Caraça J., Lundvall B., Mendonça S. (2009) The changing role of science in the innovation process: From queen to Cinderella? Technological Forecasting and Social Change, vol. 76, no 6, pp. 861-867.

Chen K., Kenney M. (2007) Universities/Research Institutes and Regional Innovation Systems: The Cases of Beijing and Shenzhen. World Development, vol. 35, no 6, pp. 1056-1074.

Clark B. (2004) Creating Entrepreneurial Universities, Oxford: IAU Press-Elsevier.

Clarysse B., Wright M., Bruneel J., Mahajan A. (2014) Creating value in ecosystems: Crossing the chasm between knowledge and business ecosystems. Research Policy, vol. 43, no 7, pp. 1164-1176.

Cohen W.M., Nelson R.R., Walsh J.P. (2002) Links and impacts: The influence of public research on industrial R\&D. Management Science, vol. 48, no 1, pp. 1-23.

Collini S. (2012) What Are Universities for?, London: Penguin.

Cooke P. (2001) Regional Innovation Systems, Clusters and the Knowledge Economy. Industrial and Corporate Change, vol. 10, no 4, pp. 945-974.

Cooke P. (2005) Regionally asymmetric knowledge capabilities and open innovation: Exploring 'globalisation 2' A new model of industry organization. Research Policy, vol. 34, no 8, pp. 1128-1149.

Cooke P. (2008) Regional innovation systems: Origin of the species. International Journal of Technological Learning, Innovation and Development, vol. 1, no 3, pp. 393-409.

Cooke P., Uranga M., Etxebarria G. (1997) Regional innovation systems: Institutional and organizational dimensions. Research Policy, vol. 26, no 4, pp. 475-491.

Cooke P., Uranga M., Etxebarria G. (1998) Regional systems of innovation: An evolutionary perspective. Environment and Planning, vol. 30, no 9, pp. 1563-1584.

Cowan R., Zinovyeva N. (2013) University effects on regional innovation. Research Policy, vol. 42, no 3, pp. 788-800.

D’Este P., Perkmann M. (2011) Why do academics engage with industry? The entrepreneurial university and individual motivations. Journal of Technology Transfer, vol. 36, no 3, pp. 316-339.

Delgado M., Porter M., Stern S. (2010) Clusters and entrepreneurship. Journal of Economic Geography, vol. 10, no 4, pp. 495-518. 
Diez J. (2000) The importance of public research institutes in innovative networks - Empirical results from the Metropolitan innovation systems Barcelona, Stockholm and Vienna. European Planning Studies, vol. 8, no 4, pp. 451-463.

Doloreux D. (2002) What we should know about regional systems of innovation. Technology in Society, vol. 24, no 3, pp. 243-263.

Doloreux D., Parto S. (2005) Regional innovation systems: Current discourse and unresolved issues. Technology in Society, vol. 27, no 2, pp. 133-153.

Dosi G. (1988) The nature of the innovative process. Technical Change and Economic Theory (eds. G. Dosi, C. Freeman, R. Nelson, G. Silverberg, L. Soete), London: Pinter, pp. 221-238.

Etzkowitz H. (1998) The norms of entrepreneurial science: Cognitive effects of the new university-industry linkages. Research Policy, vol. 27, no 8, pp. 823-833.

Etzkowitz H. (2004) The evolution of the entrepreneurial university. International Journal of Technology and Globalization, vol. 1, no 1, pp. 64-77.

Etzkowitz H., Leydesdorff L. (2000) The dynamics of innovation: From National Systems and "Mode 2" to a Triple Helix of university-industry-government relations. Research Policy, vol. 29, no 2, pp. 109-123.

Feldman M.P. (2001) The Entrepreneurial Event Revisited: Firm Formation in a Regional Context. Industrial and Corporate Change, vol. 10, no 4, pp. 861-891.

Fischer B. (2015) On the Contributions of Knowledge-Intensive Business-Services Multinationals to Laggard Innovation Systems. Brazilian Administration Review, vol. 12, no 2, pp. 150-168.

Fischer B., Schaeffer P., Phaiffer J. (2018a) Universities' gravitational effects on the location of knowledge-intensive investments in Brazil. Science and Public Policy, forthcoming. Pre-print available online at: https://doi.org/10.1093/ scipol/scy002, accessed 29.03.2018.

Fischer, B., Queiroz S., Vonortas N. (2018b) On the location of knowledge-intensive entrepreneurship in developing countries: Lessons from São Paulo, Brazil. Entrepreneurship and Regional Development, forthcoming. Pre-print available online at: https://doi.org/10.1080/08985626.2018.1438523, accessed 29.03.2018.

Fischer B., Schaeffer P., Vonortas N., Queiroz S. (2018c) Quality comes first: University-industry collaboration as a source of academic entrepreneurship in a developing country. Journal of Technology Transfer, vol. 43, no 2, pp. 263-284.

Florida R., Mellander C. (2014) Rise of the startup city: The changing geography of the venture capital financed innovation (Working Paper no 377), Jönköping, Sweden: Centre of Excellence for Science and Innovation Studies.

Fritsch M. (2001) Co-operation in regional innovation systems. Regional Studies, vol. 35, no 4, pp. 297-307.

Fritsch M. (2005) Do regional systems of innovation matter? The New Economy in Transatlantic Perspective: Spaces of Innovation (ed. K. Huebner), London: Taylor \& Francis, pp. 189-206.

Fritsch M., Schwirten C. (2006) Enterprise-University co-operation and the role of public research institutions in regional innovation systems. Industry and Innovation, vol. 6, no 1, pp. 69-83.

Fritsch M., Slavtchev V. (2007) Universities and innovation in space. Industry and Innovation, vol. 14, no 2, pp. 201-218.

Galan-Muros V., Davey T. (2017) The UBC ecosystem: Putting together a comprehensive framework for universitybusiness cooperation. Journal of Technology Transfer, forthcoming. Pre-print available online at: https://link. springer.com/article/10.1007/s10961-017-9562-3, accessed 29.03.2018.

Giuliani E. (2013) Network Dynamics in Regional Cluster: Evidence from Chile. Research Policy, vol. 42, no 8, pp. $1406-1419$.

Guerrero M., Urbano D., Fayolle A., Klofsten M., Mian S. (2016) Entrepreneurial universities: Emerging models in the new social and economic landscape. Small Business Economics, vol. 47, no 3, pp. 551-563.

Harrison R.T., Leitch C. (2010) Voodoo institution or entrepreneurial university? Spin-offs companies, the entrepreneurial system and regional development in the UK. Regional Studies, vol. 44, no 9, pp. 1241-1262.

Hicks D., Breitzman T., Olivastro D., Hamilton K. (2001) The changing composition of innovative activity in the US: A portrait based on patent analysis. Research Policy, vol. 30, no 4, pp. 681-703.

Hong W. (2008) Decline of the center: The decentralizing process of knowledge transfer of Chinese universities from 1985 to 2004. Research Policy, vol. 37, no 4, pp. 580-595.

Jackson D.J. (2011) What is an Innovation Ecosystem, Arlington, VA: National Science Foundation.

Jaffe A.B. (1989) Real effects of academic research. The American Economic Review, vol. 79, no 5, pp. 957-970.

Jiao H., Zhou J., Gao T., Liu X. (2016) The more interactions the better? The moderating effect of the interaction between local producers and users of knowledge on the relationship between $R \& D$ investment and regional innovation systems. Technological Forecasting and Social Change, vol. 110, pp. 13-20.

Laursen K., Reichstein T., Salter A. (2011) Exploring the effect of geographical proximity and university quality on university-industry collaboration in the United Kingdom. Regional Studies, vol. 45, no 4, pp. 507-523.

Leydesdorff L., Fritsch M. (2006) Measuring the knowledge base of regional innovation systems in Germany in terms of a Triple Helix dynamics. Research Policy, vol. 35, no 10, pp. 1538-1553.

Li X. (2009) China's regional innovation capacity in transition: An empirical approach. Research Policy, vol. 38, no 2, pp. 338-357.

Mazzoleni R., Nelson R. (2007) The roles of research at universities and public labs in economic catch-up. Research Policy, vol. 36, no 10, pp. 1512-1528. 
Moodysson J., Coenen L., Asheim B. (2008) Explaining spatial patterns of innovation: Analytical and synthetic modes of knowledge creation in the Medicon Valley life-science cluster. Environmental Planning A, vol. 40, no 5, pp. 1040-1056.

Mowery D.C., Sampat B.N. (2005) Universities in national systems. The Oxford Handbook of Innovation (eds. J. Fagerberg, D. Mowery, R. Nelson), Oxford: Oxford University Press, pp. 209-239.

Ortega-Argilés R., Potters L., Vivarelli M. (2011) R\&D and productivity: Testing sectoral peculiarities using micro data. Empirical Economics, vol. 41, no 3, pp. 817-839.

Perkmann M., Tartari V., McKelvey M., Autio E., Broström A., D’Este P., Fini R., Geuna A., Grimaldi R., Hughes A., Krabel S., Kitson M., Llerena P., Lissoni F., Salter A., Sobrero M. (2013) Academic engagement and commercialisation: A review of the literature on university-industry relations. Research Policy, vol. 42, no 2, pp. 423-442.

Poods R., Oort F., Frenken K. (2010) Innovation, spillovers and university-industry collaboration: An extended knowledge production function approach. Journal of Economic Geography, vol. 10, no 2, pp. 231-255.

Qian H., Ács Z., Stough R. (2013) Regional systems of entrepreneurship: The nexus of human capital, knowledge and new firm formation. Journal of Economic Geography, vol. 13, no 4, pp. 559-587.

Rapini M.S., Albuquerque E.D.M., Chave C.V., Silva L.A., Souza S.G.A., Righi H.M., Cruz W.M.S. (2009) Universityindustry interactions in an immature system of innovation: Evidence from Minais Gerais, Brazil. Science and Public Policy, vol. 36, no 5, pp. 373-386.

Saxenian A.L. (2006) The New Argonauts: Regional advantage in a global economy, Cambridge (MA): Harvard University Press.

Siegel D.S., Wright M. (2015) Academic Entrepreneurship: Time for a Rethink? British Journal of Management, vol. 26, no 4, pp. 582-595.

Suzigan W., Albuquerque E. (2011) The underestimated role of universities for the Brazilian system of innovation. Brazilian Journal of Political Economy, vol. 31, no 1, pp. 3-30.

Suzigan W., Albuquerque E., Garcia R., Rapini M. (2009) University and industry linkages in Brazil: Some preliminary and descriptive results. Seoul Journal of Economics, vol. 22, no 4, pp. 591-611.

Uyarra E. (2010) What is evolutionary about 'regional systems of innovation'? Implications for regional policy. Journal of Evolutionary Economics, vol. 20, pp. 115-137.

Wal A.L.J.T., Boschma R. (2009) Applying social network analysis in economic geography: Framing some key analytic issues. Annals of Regional Science, vol. 43, no 3, pp. 739-756.

WEF (2013) Entrepreneurial Ecosystems Around the Globe and Company Growth Dynamics, Geneva: World Economic Forum.

WEF (2014) Entrepreneurial Ecosystems and around the Globe and Early-stage Company Growth Dynamics: An Entrepreneurs Perspective, Geneva: World Economic Forum.

Xu G., Wu Y., Minshall T., Zhou Y. (2017) Exploring innovation ecosystems across science, technology, and business: A case of 3D printing in China. Technological Forecasting and Social Change, forthcoming. Pre-print available online at: https://doi.org/10.1016/j.techfore.2017.06.030, accessed 29.03.2018.

Youtie J., Shapira P. (2008) Building an innovation hub: A case study of the transformation of university roles in regional technological and economic development. Research Policy, vol. 37, no 8, pp. 1188-1204. 